San Jose State University

From the SelectedWorks of David W. Parent

October, 2018

\title{
Integration of an electrical engineering capstone course with social justice and global studies
}

David W Parent, San Jose State University

Patricia Backer, San Jose State University 


\section{Integration of an electrical engineering capstone course with social justice and global studies}

\author{
David Wahlgren Parent \\ Electrical Engineering Department \\ San Jóse State University \\ Jóse Jose, CA \\ David.Parent@sjsu.edu
}

\author{
Patricia Backer \\ Aviation and Technology Department \\ San Jóse State University \\ San Jóse, CA \\ Pat.Backer@sjsu.edu
}

\begin{abstract}
A four course package (six units total) consisting of two general education (GE) classes and two electrical engineering capstone classes that are taught in a highly integrated manner, that not only meets university GE requirements, but also meets the new ABET criteria in which the need to address a societal need is embedded with design criteria. The prompts for the new integrated GE/capstone Assessment results are also presented, along with methods to increase student motivation for studying GE.
\end{abstract}

Index Terms - Capstone, senior project, diversity, social justice, global studies, ABET

\section{INTRODUCTION}

In this work, which is intended to be a Full Paper in the Innovative Practice Category, an electrical engineering capstone design course that is integrated with advanced upper division general education (GE) is presented. The integrated package consists of four separate courses in a two semester sequence, where two of the courses are taught by electrical engineering faulty and two are taught by social science faculty.

Courses that combining GE topics with engineering or STEM content have been presented in the literature for many years [1-11], and there have been GE only capstone programs that have been successful [12-15], but there seem to be no multi-course package that combines GE and an engineering capstone course. This work is important because future engineers need to take into account societal needs when designing a product. This is codified in the new ABET standards of 208-2019 [16], where the GE type criteria are more embedded in the criteria, rather than called out in a sections called "soft" outcomes $[17,18]$.

The first semester of the integrated package consists of a one unit electrical engineering course, in which students develop a proposal for a team project and a one unit upper division general education course in which students learn about self, society and equality in the US (social justice). (Note: All engineering programs that participate in the integration enroll in this course.) The following semester, the students complete a three unit electrical engineering course in which the students implement their proposed project and a one unit upper division general education course(Again all participating majors enroll in this course as well.), in which students learn about culture, civilization and global understanding (global studies). Each major has their own capstone course.

The first semester integration of general education and engineering can be seen in figure 1 . The general education topics (GE) are introduced in the one unit GE courses, and then after receiving further instruction from the EE faculty, students complete GE assignments that have a technical context.

While the original impetus for this integration was to help reduce the number of units students needed to graduate from 138 to 120 units, it is felt that teaching students in this manner is superior to the traditional method of teaching advanced GE, because the electrical engineering faculty demonstrate the importance of advanced GE by teaching advanced GE.

This integration was first piloted by all the departments in the college of engineering in the fall of 2013 and was approved as a permanent package to meet upper division general education requirements in the fall of 2017 for select majors. Prior to fall 2013, the criteria used to judge a senior project proposal were the need, novelty, feasibility and appropriateness (EE skills and level) of the project. After the integration was piloted/implemented, the criteria were expanded to include whether the project addressed social issues in the United States and at least two other countries. 


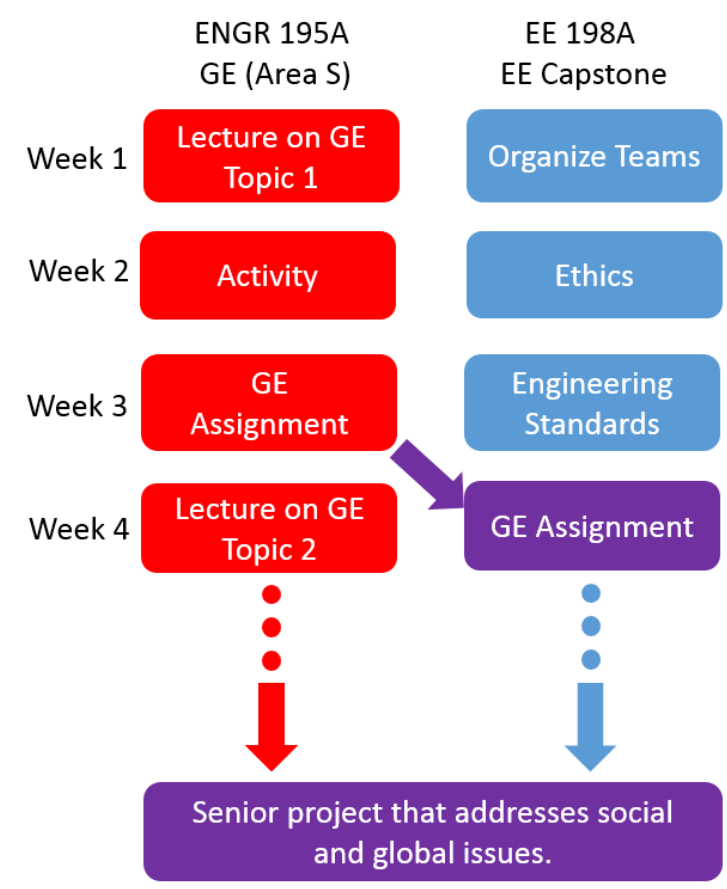

Fig 1: Integration flow of senior project and GE classes.

The rest of the paper will document in more detail how the course is implemented and how the course "flows", without much detail on the GE learning objectives or assignments (section 2). The details of the GE learning objectives and the assignments used to access them are then given in section three. Section 4 will detail how this new package implements the new ABET criteria. Section 5 will present some assessment results.

\section{PACKage ImPlementation Details}

One of the main concerns the committee that approves GE courses at the authors' institution was that engineering faculty did not have the skills to teach GE, or would not treat the topic seriously ${ }^{1}$. To minimize these fears and to develop a comprehensive meaningful senior project upper division GE integration package, the following measures were taken:

- The one unit GE companion classes were developed by humanities faculty supported by the college of engineering.

- Engineering faculty sat in on the one unit GE classes the first semester they were taught so that they could understand the topics from a nonengineering perspective.

- The college of engineering held meetings twice a semester to train faculty on how to grade GE assignments. One activity was for faculty to grade a "good paper" and one "bad paper" and see if the faculty graded in the same fashion as the GE content expert.

- The college of engineering paid the GE faculty "extra" to teach these one unit, large section courses.
- The senior project courses and GE companion courses all use Canvas shells that:

- Have common rubrics that make sure that grading is uniform.

- Have common outcomes and learning objectives so that assessment can be done at the college level, not just the course level.

- All assignments, notes and syllabi so that to minimize confusion when switching instructors.

- Videos were created on how to run/teach the EE senior project course to further minimize confusion when switching instructors.

To adopt the GE integration to a level beyond what was required by the GE committee, electrical engineering projects were changed so that they had to address a societal need at some level. Having each project address a social issue was accomplished by the author meeting with each team to help them see how their project addressed a social issue, or to choose a project that automatically did. Some projects were hard to see the obvious societal needs they addressed. For instance, there was a project to develop an 18 channel, $20 \mathrm{GHz}$ oscilloscope on a card as part of a student's internship at Linear Technology. To find the societal need, the products that this new test step up would verify were used to show how the project addressed a societal need. Some projects address an obvious societal need such as device that would track garbage in a local waterway. Another popular project that addressed a societal need was electronics to keep Alzheimer's patients safe and in their homes for as long as possible. In almost all cases in order for the project to truly help society, the product would have to be manufactured at scale, which would happen after graduation. The full list of spring 2017 senior projects and what societal need they addressed can be seen in Table 1 .

Table 1: List of senior project titles and how they address a societal need for spring 2017.

\begin{tabular}{|l|l|}
\hline Project Title & Societal need addressed \\
\hline Automated Delivery Car & $\begin{array}{l}\text { Cart is used to reduce } \\
\text { medical mistakes by } \\
\text { automatized medicine } \\
\text { delivery. }\end{array}$ \\
\hline Automated Fire Detection & $\begin{array}{l}\text { Housing is severely limited } \\
\text { in our area, this detects and } \\
\text { extinguishes home } \\
\text { damaging fires. }\end{array}$ \\
\hline Automated Vent Covers: & $\begin{array}{l}\text { Control system to reduce } \\
\text { residential heating and } \\
\text { cooling carbon footprint }\end{array}$ \\
\hline Boar Detector & $\begin{array}{l}\text { Wild boars spread e-coli in } \\
\text { local farms. }\end{array}$ \\
\hline
\end{tabular}




\begin{tabular}{|c|c|}
\hline $\begin{array}{l}\text { Energy Harvesting } \\
\text { Research }\end{array}$ & $\begin{array}{l}\text { Reduce need for batteries } \\
\text { and thus e-waste }\end{array}$ \\
\hline $\begin{array}{l}\text { Mesh Sensor Network for } \\
\text { Smart City }\end{array}$ & $\begin{array}{l}\text { Increase safety in city } \\
\text { without racial profiling }\end{array}$ \\
\hline $\begin{array}{l}\text { Hafnium Oxide films for } \\
\text { Bio-Interfacing }\end{array}$ & $\begin{array}{l}\text { Long term: neural control } \\
\text { of prosthetics }\end{array}$ \\
\hline $\begin{array}{l}\text { Navigation solution for } \\
\text { the blind }\end{array}$ & $\begin{array}{l}\text { Electronic cane to enhance } \\
\text { mobility of blind persons }\end{array}$ \\
\hline $\begin{array}{l}\text { Novel Control Algorithms } \\
\text { for Hot water heaters }\end{array}$ & $\begin{array}{l}\text { Reduce energy } \\
\text { consumption thus carbon } \\
\text { foot print }\end{array}$ \\
\hline $\begin{array}{l}\text { Portable Ultra-Violet } \\
\text { Tracker }\end{array}$ & Prevent skin cancer \\
\hline Pothole Detector & $\begin{array}{l}\text { Prevents low income } \\
\text { people from having to get a } \\
\text { "pay day" loan to repair } \\
\text { damage caused by } \\
\text { potholes. }\end{array}$ \\
\hline $\begin{array}{l}\text { Reward drivers for 'good' } \\
\text { behavior }\end{array}$ & $\begin{array}{l}\text { Prevent accidents by } \\
\text { encouraging proper } \\
\text { behavior such as merging }\end{array}$ \\
\hline Smart Bicycle Trailer & $\begin{array}{l}\text { Reduce need for a car, thus } \\
\text { reduces carbon footprint }\end{array}$ \\
\hline Smart Evacuation System & $\begin{array}{l}\text { Helps people escape a } \\
\text { building during a natural } \\
\text { disaster or fire }\end{array}$ \\
\hline $\begin{array}{l}\text { Touch-free Vitals } \\
\text { measurement device }\end{array}$ & $\begin{array}{l}\text { Help with triage during a } \\
\text { natural disaster }\end{array}$ \\
\hline $\begin{array}{l}\text { Voice controlled indoor } \\
\text { navigation guide for the } \\
\text { blind }\end{array}$ & $\begin{array}{l}\text { Enhance mobility for blind } \\
\text { persons }\end{array}$ \\
\hline $\begin{array}{l}\text { Voice-controlled } \\
\text { articulating camera }\end{array}$ & Used to prevent car thefts. \\
\hline
\end{tabular}

While a small portion of the integrated, back and forth nature of four course package to meet capstone and GE requirements can be seen in figure 1 , to help better promote this package more information needs to be given. The capstone EE 198A course is taken with the companion GE course ENGR 195A and while they start learning about the GE topics in the GE companion course, they are forming project teams in the engineering capstone course by selecting an advisor, finding team mates (students choose their own groups) and finding a problem to solve. After about three weeks, the problem to be solved is selected by the teams and the students begin the literature review with their project advisor. At this time the first GE assignment is due in the companion GE course and a few weeks later a GE assignment in the capstone course is due. The students meet with their project advisor before the GE assignment is due to make sure their project addresses a societal need. Other engineering topics that are taught during this phase are engineering ethics and engineering standards.

After this preliminary stage, the students continue to learn GE topics from the GE companion course and have assignments in both companion GE and capstone courses. A pre-proposal in the form of a group business plan and the final GE assignments are then due. The first semester wraps up with group oral presentations and written proposals.

If a student does not pass the companion GE class they can repeat it the next semester. If they do not pass the capstone class they have to repeat the capstone class only.

The second semester consists of another GE companion course that deal with global issues and execution phase of senior project. The back and forth nature of the courses is similar to the one shown in figure 1 . The difference is that the capstone engineering course is mostly weekly meetings with the advisor, two formal GE meetings with the advisor and time spent implementing a prototype of the project. About halfway through the semester the students present their projects to future EE students at an open house event. The last two weeks the students present their final project results and write a formal final report.

\section{GENERAL EDUCATION DETAILS}

The authors' institution requires 12 semester units of upper division GE:

- $\quad$ Area R: Earth and Environment (3 units)

- $\quad$ Area S: Self, Society, \& Equality in the U.S. (3 units)

- $\quad$ Area V: Culture, Civilization, and Global Understanding (3 units)

- $\quad$ Area Z: Written Communication 2 (3 units)

Even though 12 units of upper division GE are required, it is possible to combine upper division units/requirements as long as the new course teaches and accesses the required learning objectives, as well as meeting the combined word counts for each area. For instance, the required engineering writing course combines $\mathrm{GE}$ areas $\mathrm{R}$ and $\mathrm{Z}$, and the total writing requirement is 6000 words (3000 per GE area). Prior to this combination package of senior project and GE areas $\mathrm{S}$ and $\mathrm{V}$, electrical engineering students would take separate area $S$ and $\mathrm{V}$ courses from a smorgasbord of offerings. After the integrated package was developed, the students would take six unit combined package to meet the upper division GE requirements and $\mathrm{ABET}$ requirements.

One GE Learning Objective (GELO) for each course covering a GE area must be accessed each year and a two page report detailing the results of the assessment must be submitted to the university. Every six years all GE courses are evaluated by the board of general studies (BOGS) to maintain certification. The six year cycle was chosen to match the ABET cycle and is part of university program planning.

\section{A. Area S: SELF, SOCIETY, \& EQUALITY IN THE U.S.}

There are four GELOs (general education learning objectives) for an area $\mathrm{S}$ course. Upon successful completion of this course, students will be able to: 
GELO 1: Students shall be able to compare systematically the ideas, values, images, cultural artifacts, economic structures, technological developments, or attitudes of people from more than one culture outside the U.S.

GELO 2: Describe historical, social, political, and economic processes producing diversity, equality, and structured inequalities in the U.S.

GELO 3: Describe social actions which have led to greater equality and social justice in the U.S. (i.e. religious, gender, ethnic, racial, class, sexual orientation, disability, and/or age).

GELO 4: Recognize and appreciate constructive interactions between people from different cultural, racial, and ethnic groups within the U.S.

There are two assignments that support GELO 1 of area S:

- $\quad$ ENGR 195A Reflection Paper 1 (500 words): Discuss and provide examples of how your identities (i.e., religious, gender, ethnic, racial, class, sexual orientation, disability and/or age, among others) are shaped by cultural and societal influences within contexts of equality and inequality.

- EE 198A 5 Year Plan (500 words): Based upon your response to Engr 195A Testimony 1, consider your identity as a future engineer. How is your identity as an engineer shaped by cultural and societal influences within contexts of equality and inequality?

There are two assignments used to teach and access GELO 2:

- ENGR 195A Refection paper 2 (750 words): Consider technological innovations in your field and describe an example of how one such innovation has either increased or decreased social justice and inequality in the U.S. Be explicit about how these outcomes manifest. Or, students may analyze a website online that is dedicated to social or environmental justice and address these same questions. Finally, discuss how your current or past projects have or will contribute to social and/or environmental justice in the United States.

- EE 198A Oral Presentation: Using the case studies provided in ENGR195A, describe how your project addresses a social issue in the U.S.

There are two assignments used to teach and access GELO 3:

- $\quad$ ENGR 195A Refection paper 2 (750 words): Consider technological innovations in your field and describe an example of how one such innovation has either increased or decreased social justice and inequality in the U.S. Be explicit about how these outcomes manifest. Or, students may analyze a website online that is dedicated to social or environmental justice and address these same questions. Finally, discuss how your current or past projects have or will contribute to social and/or environmental justice in the United States.

- EE 198A Refection paper 1 (500 words): Describe social actions which have led to greater equality and social justice in the U.S. (i.e. religious, gender, ethnic, racial, class, sexual orientation, disability, and/or age).

GELO 4 of area $\mathrm{S}$ is only taught/accessed in the GE specific course ENGR 195A:

- $\quad$ Engr 195A Reflection Paper 3 (500 words): Students will read excerpts from Ernest Callenbach's Ecotopia. Students will apply this reading to their current lived experience in the U.S. Beyond fulfilling the GELO 4, students will address the specific course learning objective "identify, compare, and contrast how local community organizations, groups, and agencies address social issues relevant to the environment and quality of life in the Santa Clara Valley" by comparing one element in our current society to Callenbach's described society.

There are more assignments in the EE senior project course than those listed which include a group business, plan group, written proposal, and documenting formal faculty/student groups meetings that discuss GE assignments, literature review and project status. There is also a skill audit exam student must pass to earn their grade in EE 198A [19].

\section{B. Area V: CULTURE, CIVILIZATION, \& GLOBAL UNDERSTANDING}

There are three GELOs (general education learning objectives) for an area V course. Upon successful completion of this course, students will be able to:

GELO 1: Students shall be able to compare systematically the ideas, values, images, cultural artifacts, economic structures, technological developments, or attitudes of people from more than one culture outside the U.S.

GELO 2: Students shall be able to identify the historical context of ideas and cultural traditions outside the U.S. and how they have influenced American culture.

GELO 3: Students shall be able to explain how a culture outside the U.S. has changed in response to internal and external pressures.

There are two assignments used to teach and access area V's GELO 1:

- ENGR 195B Reflection Paper 1 (750 words): Consider the ways in which small, rural, farmers in Mexico and India might be affected by the introduction of genetically modified crops. Oftentimes, the introduction of such technologies require small, rural, farmers to adapt or change their lifestyles, that is, the way they work, where they work, and how they live. Is there 
anything morally problematic, or morally questionable, about this? If there is, what is it? If there is not, please explain.

- EE 198B Refection paper 1(750 words): Assume that your project is about to turn into a successful company. Using the studies provided in ENGR195A/B as a background, write about how to take into account at least two aspects (for example ideas, values, images, cultural artifacts, economic structures, or technological developments) while evaluating your decision to manufacture your product in two other countries.

There are two assignments used to teach and access area V's GELO 2:

- ENGR 195B Reflection Paper 1 (750 words): This paper was sued to access two GELOS.

- EE 198B Refection paper 2(750 words): Assume that your project is about to turn into a successful company. Using the studies provided in ENGR195A/B as a background, write about how to take into account at least two aspects (for example ideas, values, images, cultural artifacts, economic structures, or technological developments) while evaluating your decision to manufacture your product in two other countries.

There is one assignment used to teach and assess area V's GELO 3:

- ENGR 195B Reflection Paper 3 (750 words): Locate some technology, such as an application, mobile technology, or non-software based technology. Do research either on (i) how that technology has had a social impact on a culture or group of people outside of the US, or (ii) on how that technology, which was, developed in the US has affected a culture outside of the US.

The other assignments that are part of the electrical engineering senior design project are:

- a midterm report which is a poster session that issues used as part of open house activities

- final group oral presentation

- final group written report

- formal faculty/student meetings relating to the GE as aspects of the project.

\section{INTEGRATION WITH NEW ABET CRITERIA}

The New ABET 2018/2019criteria that are supported the integrated GE/EE senor project course are bolded in the following list of new ABET criteria:

1. an ability to identify, formulate, and solve complex engineering problems by applying principles of engineering, science, and mathematics

2. an ability to apply engineering design to produce solutions that meet specified needs with consideration of public health, safety, and welfare, as well as global, cultural, social, environmental, and economic factors

3. an ability to communicate effectively with a range of audiences

4. an ability to recognize ethical and professional responsibilities in engineering situations and make informed judgments, which must consider the impact of engineering solutions in global, economic, environmental, and societal contexts

5. an ability to function effectively on a team whose members together provide leadership, create a collaborative and inclusive environment, establish goals, plan tasks, and meet objectives

6. an ability to develop and conduct appropriate experimentation, analyze and interpret data, and use engineering judgment to draw conclusions

7. an ability to acquire and apply new knowledge as needed, using appropriate learning strategies.

In the past the electrical engineering senior project sequence was used to access many of the ABET criteria at an advanced level. This continues with the new ABET criteria, but the combined EE/GE senior project package meets the new criteria in a more meaningful manner. The area $S \& V$ GELOs support Criteria 2 and 4 directly and the fact that the electrical engineering students write papers that are graded by the humanities faculty teaching the one unit GE companion classes ensure that students can meet criteria three. The S\&V GELOs also support criteria five by teaching students how to create a "collaborative and inclusive environment".

\section{ASSESSMENT RESULTS AND DISCUSSION}

In the spring of 2016, when assessment procedures were more finalized, the percentage of projects that fully addressed a social issue was $40 \%$, mostly addressed a social issues was $27 \%$, and the percentage that weakly addressed a social issue was $33 \%$. After improvements were made to project selection process, the percentage of projects that fully addressed a social issue climbed to $94 \%$, while the mostly addressed percentage dropped to $6 \%$. The percentage of projects that weakly addressed social issues dropped to $0 \%$. A typical graph that canvas can provide after direct assessment, is shown in fig 2 . 


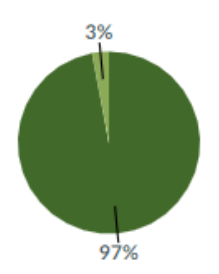

Makes a strong case that the project will address an important social issue. Somewhat makes a strong case that the project will address an important social issue. Makes no case.

Figure 2: Assessment results of how well a project meets GE area $S$ and ABET criteria 2 and 4, EE 198A spring 2017

Each semester it seemed that too many students did not take the GE writing assignments seriously. Some would not include any identifiable thesis statement that could be proved, or would address a completely different topic, even though a detailed rubric was provided. This was addressed in two ways. The first is that as part of the GE approval for the capstone/GE integration package was the requirement that all GE assignments must be passed with a $70 \%$ or the student would not pass the capstone course. While this was not enforced as the pilot was brought on line, as soon as the faculty informed the students of this policy, student effort on these assignments increased dramatically. The other method to improve student work in this area was to provide sample assignments.

Interestingly the faculty who did not believe in the capstone/GE package would complain that the writing assignments were too hard, or too harshly graded. Ultimately the departments who felt this way dropped the capstone/GE integration package even if it meant dropping technical units. (At the time, all engineering programs had to reduce the units required for a degree to 120.) On the other hand, in departments with strong faculty buy-in, student performance seemed to be greater. These particular results are anecdotal and would require more study to prove one way or another.

There was student push back at first as well. The first semester the pilot GE classes were offered, the humanities faculty reported that many male students were very resistant to talk about gender issues. This resistance persisted for another semester, but since spring 2014 there have been no reports of this.

\section{CONCLUSIONS AND FUTURE WORK}

The EE capstone courses have been successfully integrated with GE to meet both university and ABET requirements. While it does take more resources than offering nonintegrated version to meet ABET objectives, our integrated approach meets the ABET objectives in a more natural and thus sustainable manner. Given that the package is integrated and needs faculty interaction to work, makes our upper division GE requirements more like a program, and not "just bunch of courses".
An unexpected result of this integration and faculty training is the fact that now all senior project faculty are GE faculty as well as engineering faculty. This fact and the idea that no one "owns" GE was used as an argument to win approval of the integration package.

The EE capstone course has already been successfully passed on to another faculty and what remains to be done is to keep the projects current and survey the students to see if their attitudes towards GE are improved. Historically engineering students do not value GE at the authors' institution and held the attitude that it was just another hurdle to graduation. Hopefully this has changed based on conversations with students during office hours.

\section{ACKNOWLEDGMENT}

The authors would like to thank E. Allen the current Dean of College of Engineering, Computer Science and Technology at Cal State Los Angeles, who came up with the idea of integrating GE and capstone courses while she was associate dean at the authors' institution.

\section{REFERENCES}

[1] R.F. Vaz and J.A. Orr, "ECE as a pre-professional undergraduate program," IEEE Transactions on Education, vol. 46, no. 4, pp. 4294332003.

[2] D.W. Parent, "University/industry relationships at San Jose State University to produce industry's ideal new hire," in Microelectronic Systems Education, 2003. Proceedings. 2003 IEEE International Conference on, 2003, pp. 87-88.

[3] Emadi and T.M. Jacobius, "Interprofessional projects in advanced automotive power systems: An integrated education and research multidisciplinary approach," IEEE Transactions on Education, vol. 47, no. 3, pp. 356-360 2004.

[4] S. Kerrigan and S. Jhaj, "Assessing general education capstone courses: An in-depth look at a nationally recognized capstone assessment model," Peer Review, vol. 9, no. 2, pp. 132007.

[5] E. O'Neill-Carrillo, W. Frey, L. Jiménez, M. Rodríguez and D. Negrón, "Social, ethical and global issues in engineering," in Frontiers in Education Conference, 2008. FIE 2008. 38th Annual, 2008, pp. S4C-6-S4C-11.

[6] R.J. Gustafson, "Work in progress-Engineering Education Innovation Center," in Frontiers in Education Conference, 2008. FIE 2008. 38th Annual, 2008, pp. T2D-12-T2D-13.

[7] E. O'Neill-Carrillo, W. Frey, C. Ortiz-Garcia, A.A. Irizarry-Rivera, M. Perez-Lugo and J.A. Colucci-Rios, "Advancing a sustainable energy ethics through stakeholder engagement," in Energy 2030 Conference, 2008. ENERGY 2008. IEEE, 2008, pp. 1-6.

[8] E. O'Neill-Carrillo, D.L. Collins, J.L. Garriga, R. Macchiavelli and J.A. Cruz, "Center for Resources in General Education (CIVIS): Towards student success in General and STEM education," in Frontiers in Education Conference, 2009. FIE'09. 39th IEEE, 2009, pp. 1-6.

[9] D. Braun, "Teaching sustainability analysis in electrical engineering lab courses," IEEE Transactions on Education, vol. 53, no. 2, pp. 243 2472010

[10] E. O'Neill-Carrillo, H.R. Zamot, M. Hernández, A.A. Irizarry-Rivera and L.O. Jiménez-Rodríguez, "Beyond traditional power systems: Energy externalities, ethics and society," in Sustainable Systems and Technology (ISSST), 2012 IEEE International Symposium on, 2012, pp. 1-6.

[11] M. Thürer, I. Tomašević, M. Stevenson, T. Qu and D. Huisingh, "A systematic review of the literature on integrating sustainability into engineering curricula," J.Clean.Prod. 2017. 
[12] N.P. Fernandez, "Assessment matters-Integration, reflection, interpretation: Realizing the goals of a general education capstone course," About Campus, vol. 11, no. 2, pp. 23-26 2006.

[13] S. Kerrigan and S. Jhaj, "Assessing general education capstone courses: An in-depth look at a nationally recognized capstone assessment model," Peer Review, vol. 9, no. 2, pp. 132007.

[14] P. Camill and K. Phillips, "Capstones and practica in environmental studies and sciences programs: Rationale and lessons learned," Journal of Environmental Studies and Sciences, vol. 1, no. 3, pp. 181 2011.

[15] P.T. McGill, "Understanding the capstone experience through the voices of students," The Journal of General Education, vol. 61, no. 4, pp. 488-504 2012.

[16] ABET ACCREDITATION POLICY AND PROCEDURE MANUAL (APPM), 2018-2019 [online]. Available: http://www.abet.org/accreditation/accreditation-criteria/accreditationpolicy-and-procedure-manual-appm-2018-2019/

[17] H.I. Abu-Mulaweh, "An assessment of ABET programme outcomes (a) to (k)," World Transactions on Engineering and Technology Education, vol. 4, no. 2, pp. 2632005.

[18] M. Castro-Sitiriche, E. O'Neill-Carrillo, C. Papadopoulos, C. PomalesGarcía, A. Santiago-Román and J. Seguel, "Work in progressLeveraging accreditation efforts to foster innovation in engineering education," in Frontiers in Education Conference (FIE), 2010 IEEE, 2010, pp. T3J-1-T3J-3

[19] D.W. Parent, "Improvements to an electrical engineering skill audit exam to improve student mastery of core EE concepts," IEEE Transactions on Education, vol. 54, no. 2, pp. 184-187 2011. 